\title{
Quantum Chemical Study of Structures, Electronic Spectrum and Nonlinear Optical Properties of Gold-pentacene Complex
}

Guochun Yang ${ }^{1}$, Liang Fang ${ }^{1}$, Ke Tan ${ }^{2}$, Shaoqing Shi ${ }^{1}$, Zhongmin Su ${ }^{1, *}$, Rongshun Wang ${ }^{1}$

1. Institute of Functional Material Chemistry, Faculty of Chemistry, Northeast Normal

University, Changchun 130024, Jilin, P.R. China

2. College of Environment Ecosystem and Engineering, Changchun University, Changchun 130022, Jilin, P.R. China

\section{Supporting Information}

1. The Au-pentacene Bond Dissociation Energies of Systems 1-4

TABLE 1: Computed Au-pentacene Bond Dissociation Energies (BDEs in Atomic Unit) of Systems 1-4

\begin{tabular}{lllll}
\hline System & Total energy & Pentacene & Gold atom & BDEs \\
\hline 1 & -982.5517124 & -846.7570016 & -135.7548893 & 0.039821455 \\
2 & -982.5485948 & -846.7592865 & -135.7548893 & 0.034419086 \\
3 & -982.5411108 & -846.7780081 & -135.7548893 & 0.008187773 \\
4 & -982.5407571 & -846.7776800 & -135.7548893 & 0.008213431 \\
\hline
\end{tabular}

2. Contour plots of the overlap of NBOs: bonding orbital (C2-C3) with Au1 anti-lone-pair orbital and anti-bonding orbital (C2-C3) with Au1 lone-pair orbital of systems 3 and 4. 

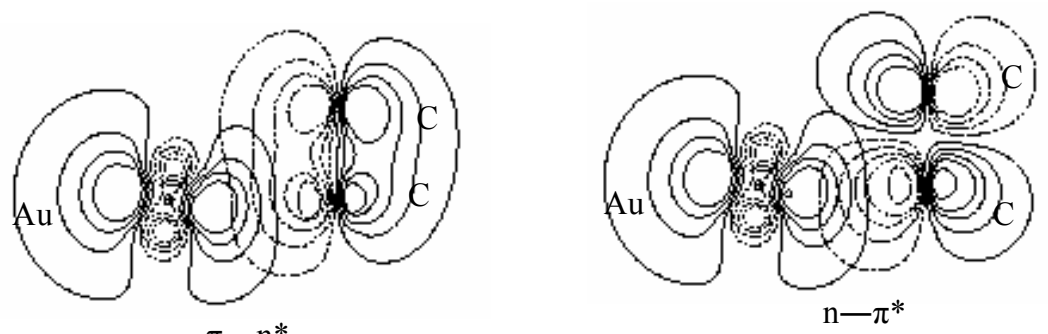

System 3
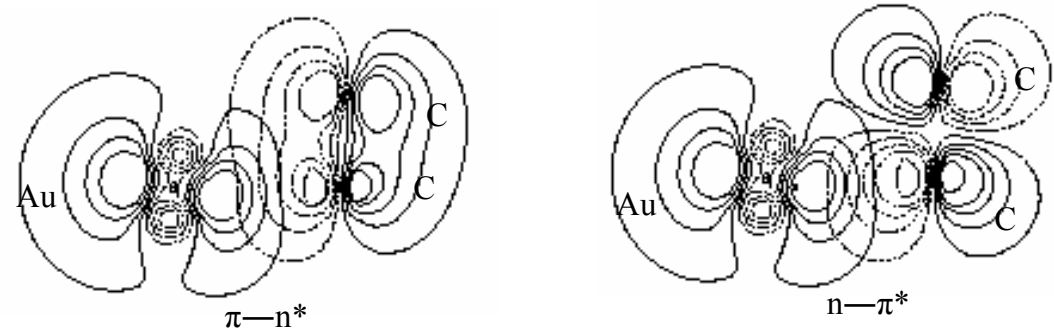

System 4

3. Bonding natures between carbon and gold atom of system 6,7 , and 8 and interactions between carbon and gold atom of system 5 .

TABLE 2: Occupancy, Orbital Hybridization (Orbital Coefficients), Wiberg bond index (WBI) and Orbital Type of Systems 6, 7, and 8.

\begin{tabular}{ccccc}
\hline systems & occupancy & orbital hybridization (orbital coefficients) & WBI & orbital type \\
\hline 6 & $0.8404(\alpha)$ & $0.8445 \mathrm{~s}^{1} \mathrm{p}^{10.00}(\mathrm{C})+0.5356 \mathrm{~s}^{1} \mathrm{~d}^{0.27}(\mathrm{Au})$ & 0.4249 & $\sigma$ \\
7 & $0.9497(\alpha)$ & $0.6955 \mathrm{~s}^{1} \mathrm{p}^{11.36}(\mathrm{C})+0.7186 \mathrm{~s}^{1} \mathrm{~d}^{0.26}(\mathrm{Au})$ & 0.7164 & $\sigma$ \\
& $0.9361(\beta)$ & $0.7253 \mathrm{~s}^{1} \mathrm{p}^{10.85}(\mathrm{C})+0.6884 \mathrm{~s}^{1} \mathrm{~d}^{0.23}(\mathrm{Au})$ & & \\
8 & $0.9438(\alpha)$ & $0.7103 \mathrm{~s}^{1} \mathrm{p}^{11.01}(\mathrm{C})+0.7039 \mathrm{~s}^{1} \mathrm{~d}^{0.26}(\mathrm{Au})$ & 0.7262 & $\sigma$ \\
& $0.9356(\beta)$ & $0.7278 \mathrm{~s}^{1} \mathrm{p}^{10.75}(\mathrm{C})+0.6858 \mathrm{~s}^{1} \mathrm{~d}^{0.25}(\mathrm{Au})$ & & \\
\hline
\end{tabular}

TABLE 3: The Second-perturbation Energy $(E(2))$ of Donnor-Acceptor Interaction with Respect to System 5

\begin{tabular}{ccccc}
\hline system & donor $(i)$ & Acceptor $(j)$ & interaction & $E(2)\left(\mathrm{KJ} \mathrm{mol}^{-1}\right)$ \\
\hline 3 & ${ }^{\mathrm{a}} \mathrm{LP}(6) \mathrm{Au} 1$ & $\mathrm{BD}^{*}(2) \mathrm{C} 2-\mathrm{C} 3$ & $n-\pi^{*}$ & 2.60 \\
& ${ }^{\mathrm{a}} \mathrm{BD}(2) \mathrm{C} 2-\mathrm{C} 3$ & $\mathrm{LP}(6) \mathrm{Au} 1$ & $\pi-n^{*}$ & 11.32 \\
\hline
\end{tabular}

${ }^{\mathrm{a}} \mathrm{BD}$ denotes the bonding orbital $(\pi)$, and $\mathrm{BD}^{*}$ denotes the formally anti-bonding orbital $\left(\pi^{*}\right)$. LP denote the lone-pair $(n)$, and LP* anti-lone-pair $\left(n^{*}\right)$ of gold atom, respectively.

4. Structures, bonding natures, and interactions of possible isomers for systems 7.

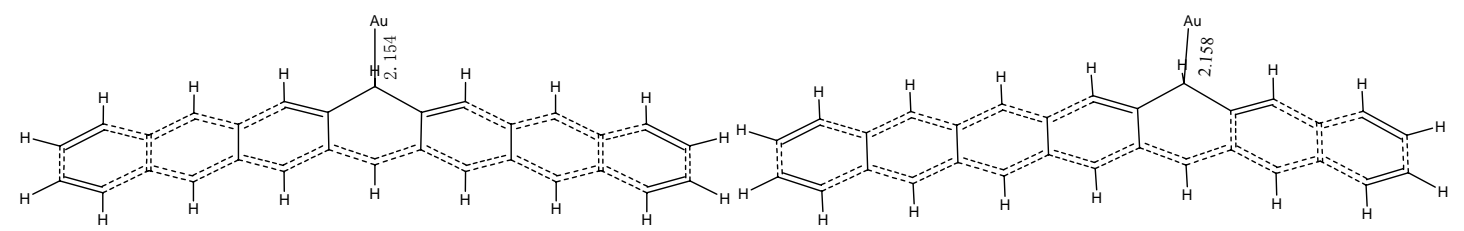


$\mathrm{AuC}_{30} \mathrm{H}_{18}-1$

$\mathrm{AuC}_{30} \mathrm{H}_{18}-2$

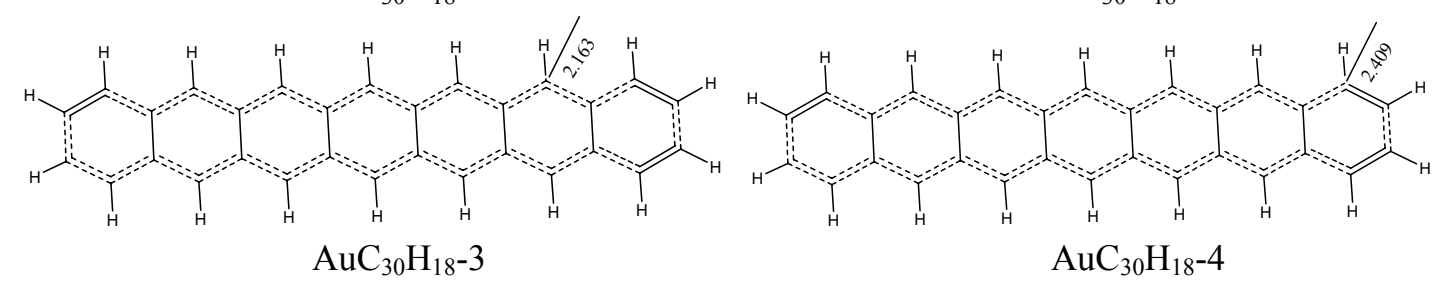

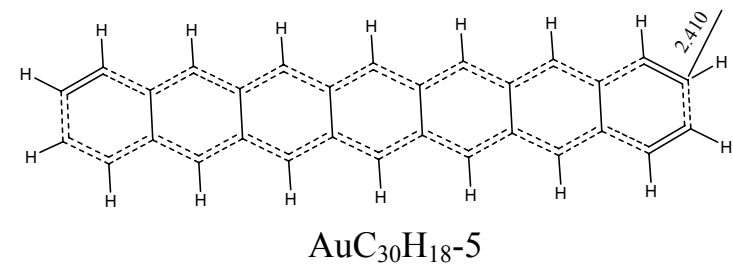

The $\mathrm{Au}-\mathrm{C}$ distances become shorter for these isomers compared to $\mathrm{AuC}_{22} \mathrm{H}_{14}$. The bonding strength and interactions between $\mathrm{Au}$ and $\mathrm{C}$ become stronger.

TABLE 4: Occupancy, Orbital Hybridization (Orbital Coefficients), Wiberg bond index (WBI) and Orbital Type of System 7.

\begin{tabular}{ccccc}
\hline systems & occupancy & orbital hybridization (orbital coefficients) & WBI & orbital type \\
\hline $7-2$ & $0.9505(\alpha)$ & $0.6883 \mathrm{~s}^{1} \mathrm{p}^{11.60}(\mathrm{C})+0.7254 \mathrm{~s}^{1} \mathrm{~d}^{0.27}(\mathrm{Au})$ & 0.7060 & $\sigma$ \\
& $0.9314(\beta)$ & $0.7348 \mathrm{~s}^{1} \mathrm{p}^{10.83}(\mathrm{C})+0.6783 \mathrm{~s}^{1} \mathrm{~d}^{0.23}(\mathrm{Au})$ & & \\
$7-3$ & $0.9407(\alpha)$ & $0.6737 \mathrm{~s}^{1} \mathrm{p}^{11.01} \mathrm{C}+0.7390 \mathrm{~s}^{1} \mathrm{~d}^{0.26}(\mathrm{Au})$ & 0.6824 & $\sigma$ \\
& $0.8938(\beta)$ & $0.7360 \mathrm{~s}^{1} \mathrm{p}^{10.75} \mathrm{C}+0.6770 \mathrm{~s}^{1} \mathrm{~d}^{0.25}(\mathrm{Au})$ & & \\
\hline
\end{tabular}

TABLE 5: The Second-perturbation Energy $(E(2))$ of Donnor-Acceptor Interaction with Respect to System 7

\begin{tabular}{ccccc}
\hline system & donor $(i)$ & Acceptor $(j)$ & interaction & $E(2)\left(\mathrm{KJ} \mathrm{mol}^{-1}\right)$ \\
\hline $7-4$ & ${ }^{\mathrm{a}} \mathrm{LP}(6) \mathrm{Au} 1$ & $\mathrm{BD} *(2) \mathrm{C} 2-\mathrm{C} 3$ & $n-\pi^{*}$ & 9.71 \\
& ${ }^{\mathrm{a}} \mathrm{BD}(2) \mathrm{C} 2-\mathrm{C} 3$ & $\mathrm{LP} *(6) \mathrm{Au} 1$ & $\pi-n^{*}$ & 31.29 \\
\multirow{2}{*}{$7-5$} & $\mathrm{LP}(6) \mathrm{Au} 1$ & $\mathrm{BD} *(2) \mathrm{C} 2-\mathrm{C} 3$ & $n-\pi^{*}$ & 12.29 \\
& $\mathrm{BD}(2) \mathrm{C} 2-\mathrm{C} 3$ & $\mathrm{LP} *(6) \mathrm{Au} 1$ & $\pi-n^{*}$ & 32.08 \\
\hline
\end{tabular}

${ }^{\mathrm{a}} \mathrm{BD}$ denotes the bonding orbital $(\pi)$, and $\mathrm{BD}^{*}$ denotes the formally anti-bonding orbital $\left(\pi^{*}\right)$. LP denote the lone-pair $(n)$, and LP* anti-lone-pair $\left(n^{*}\right)$ of gold atom, respectively.

5. The frontier molecular orbitals constitute main absorption to our studied systems.

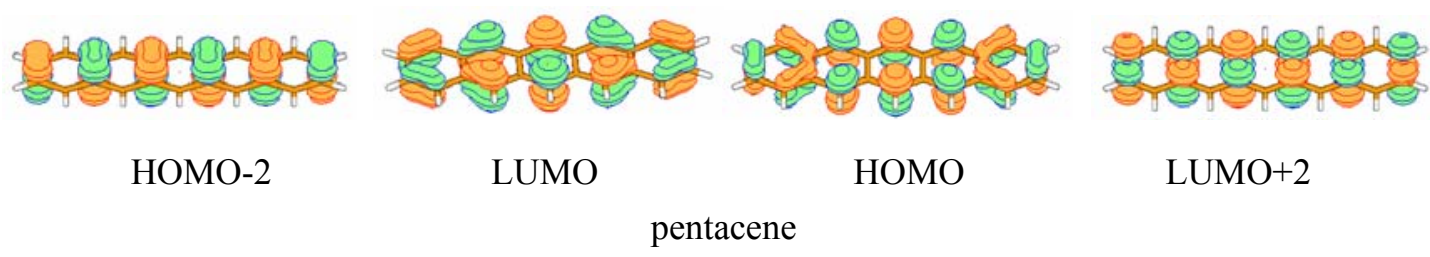




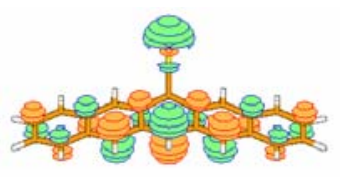

$\alpha \mathrm{HOMO}$

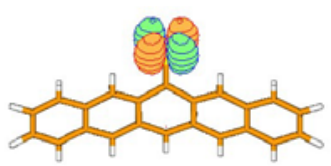

$\alpha$ HOMO-6

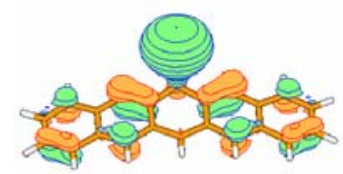

$\alpha$ HOMO-1

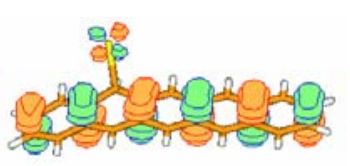

$\beta$ HOMO

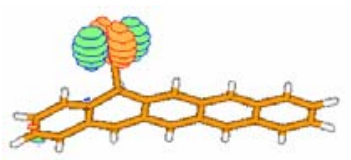

$\beta$ HOMO-6

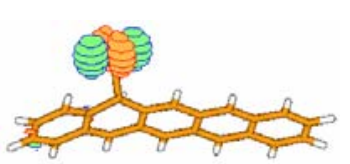

$\alpha$ HOMO-3

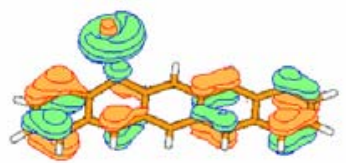

$\alpha$ HOMO-2

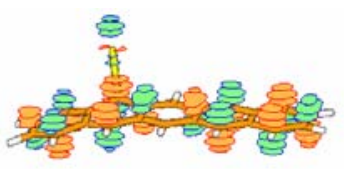

$\beta$ HOMO

$$
\beta \text { LUMO+1 }
$$

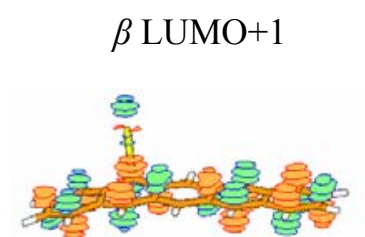

$\alpha$ LUMO +1

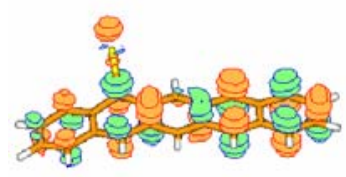

$\alpha$ LUMO+1

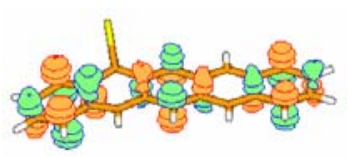

$\beta$ LUMO +5

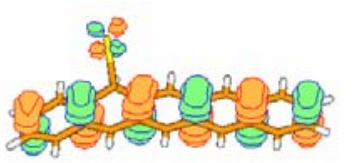

$\beta$ HOMO-1

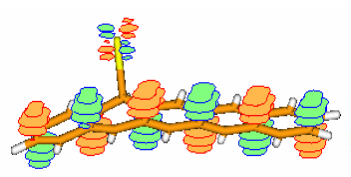

$\beta$ HOMO-2

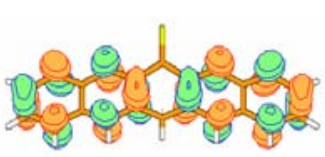

$\alpha \mathrm{LUMO}+1$

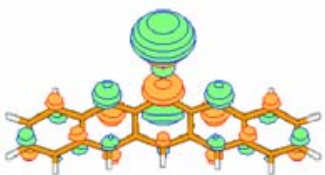

$\alpha$ LUMO+1

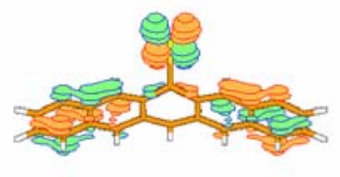

$\beta$ HOMO-7

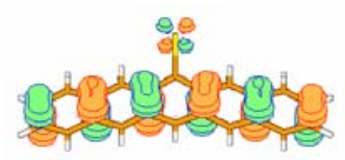

$\beta$ HOMO-2

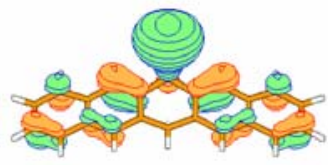

$\beta$ HOMO

$\alpha \mathrm{LUMO}+3$

System 1

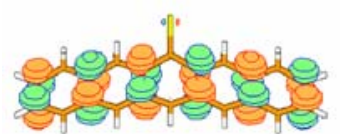

$$
\alpha \mathrm{LUMO}+3
$$$$
\text { System } 1
$$

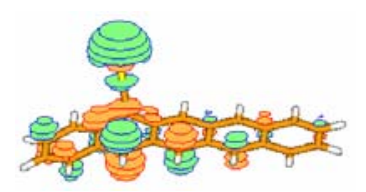

$$
\beta \text { LUMO }
$$

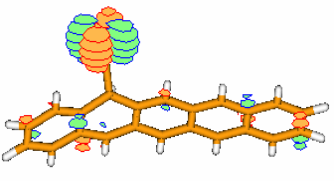

$$
\beta \text { HOMO-5 }
$$
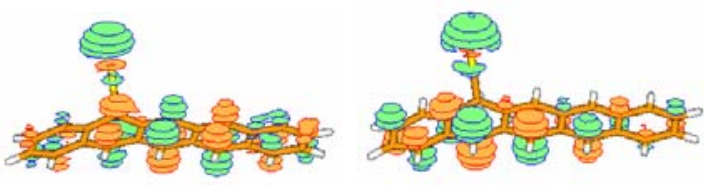

$\alpha$ HOMO

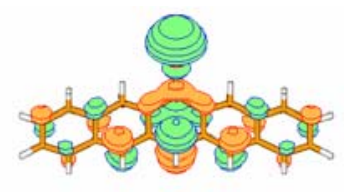

$$
\beta \text { LUMO }
$$

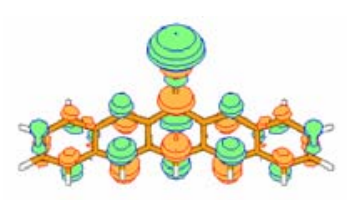

$\beta$ LUMO+1

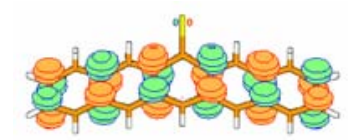

$\beta$ LUMO +4

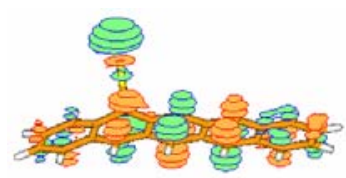

$\beta$ LUMO+1

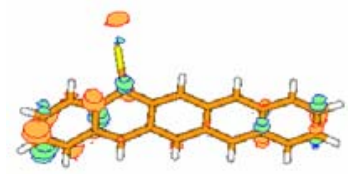

$$
\alpha \text { LUMO+7 }
$$

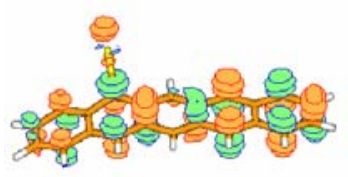

$\beta$ LUMO+2

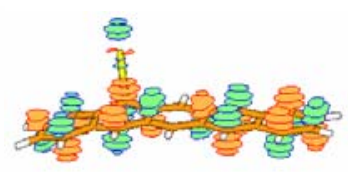

$\beta$ LUMO +2

System 2 

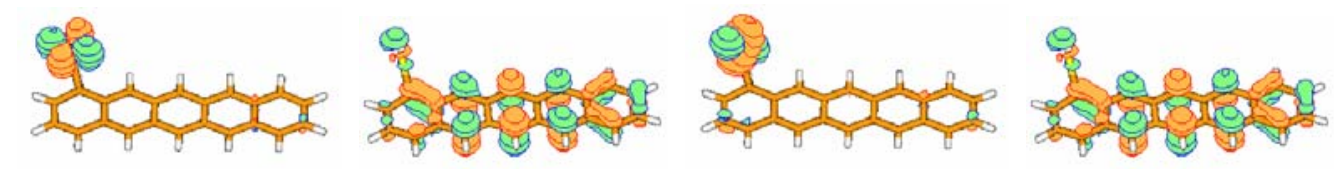

$\beta$ HOMO-4

$\beta$ LUMO+1

$\beta$ HOMO-6

$\beta$ LUMO +1
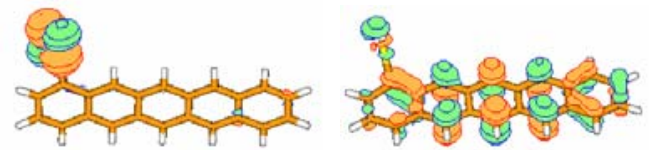

go

$\alpha \mathrm{LUMO}+6$

$\beta$ HOMO-7

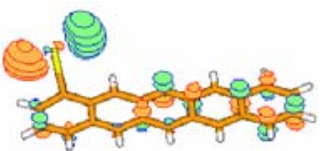

$\beta$ LUMO+1
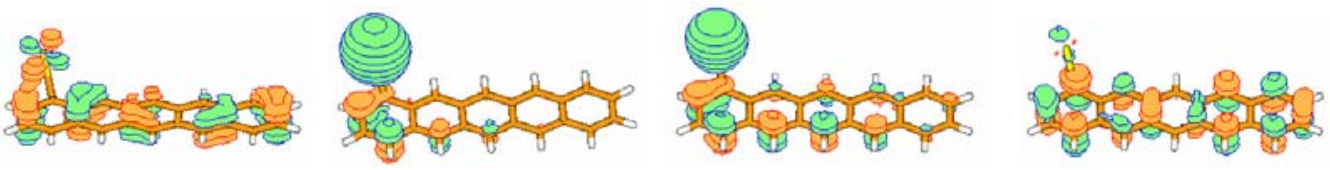

$\beta$ HOMO-9

$\beta$ LUMO

$\alpha$ HOMO-3

$\alpha \mathrm{LUMO}+1$
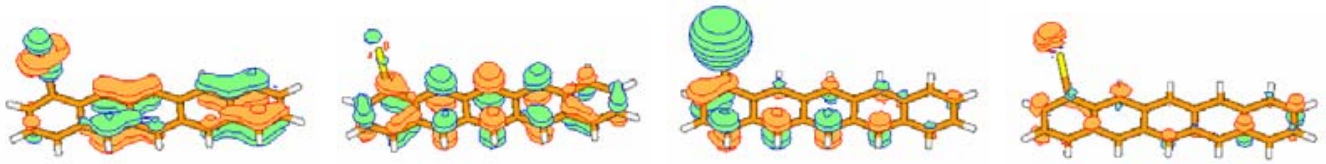

$\alpha$ HOMO-9

$\alpha$ LUMO

$\alpha$ HOMO

$\alpha \mathrm{LUMO}+6$
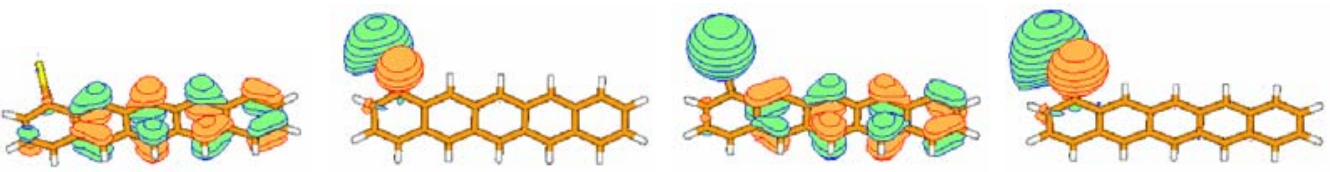

$\alpha$ HOMO-1

$\alpha \mathrm{LUMO}+4$

$\beta$ HOMO

$\beta \mathrm{LUMO}+5$

System 3
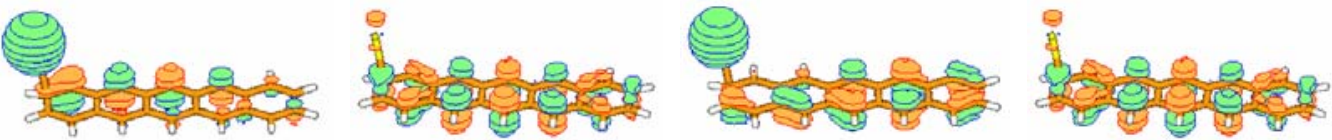

$\alpha$ HOMO

$\alpha$ LUMO

$\alpha$ HOMO-1

$\alpha$ LUMO

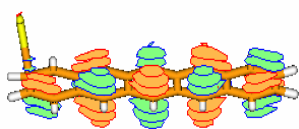
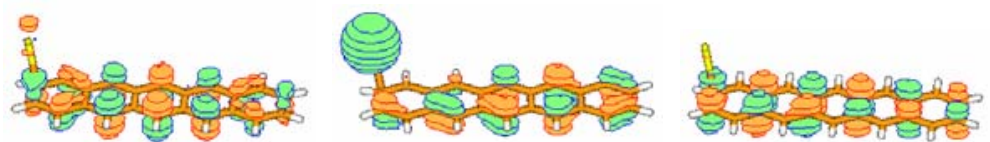

$\beta$ HOMO

$\beta \mathrm{LUMO}+1$

$\alpha$ HOMO-1

$\alpha \mathrm{LUMO}+2$
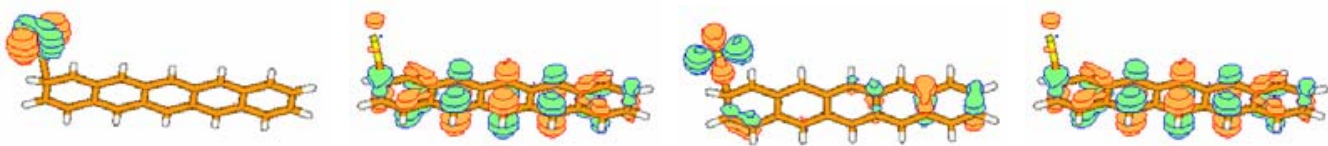

$\alpha$ HOMO-6

$\alpha$ LUMO

$\beta$ HOMO-4

$\beta$ LUMO+1
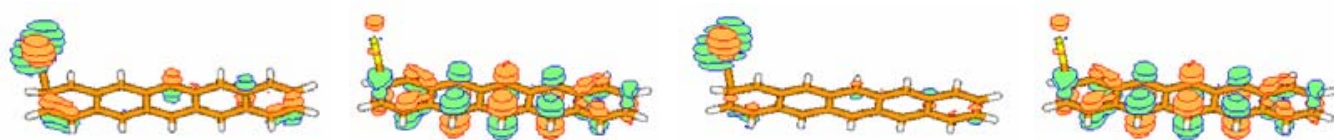

$\alpha$ HOMO-7

$\alpha$ LUMO

$\beta$ HOMO-6

$\beta$ LUMO +1

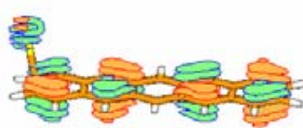

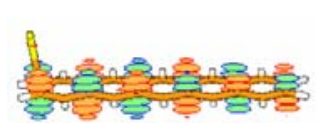
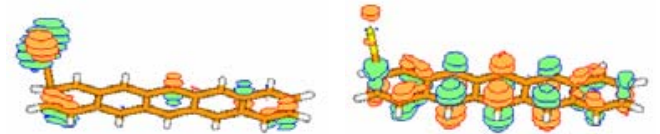


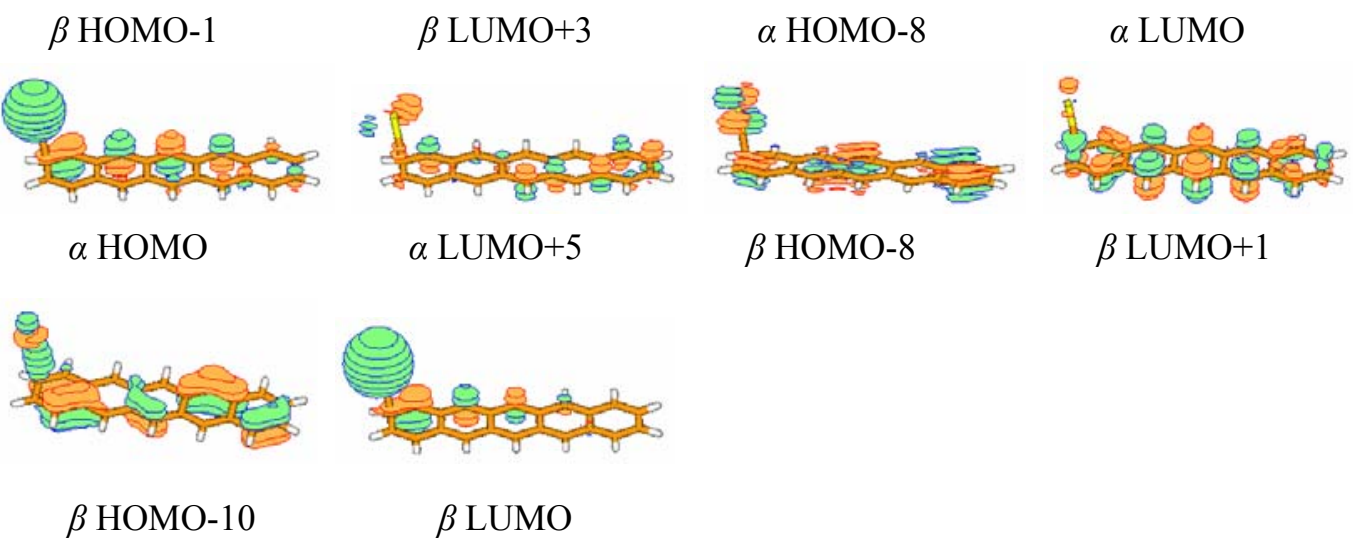

System 4

6. Convergent behaviors

It is necessary to investigate the convergent behavior in the summation of excited states and determine whether the results calculated from our methods are reliable for these systems. In principle, the more excited states participate in the calculation, the more accuracy of the result will be obtained. When the excited state number is gradually increased, the denominator of eq. 1 become larger and larger, the numerator variation is very small. Hence, the second-order polarisability converges rapidly with the number of excited states included. Figure 1 presents the plots of the $\beta$ values verses the number of states for the systems 1-4. It can be seen that the convergence is stable after summation over about 60 states. Other systems also have the similar convergent behaviors. Accordingly, it is reasonable approximation in the calculation of $\beta$ values by employing 100 states in the SOS method in this work.
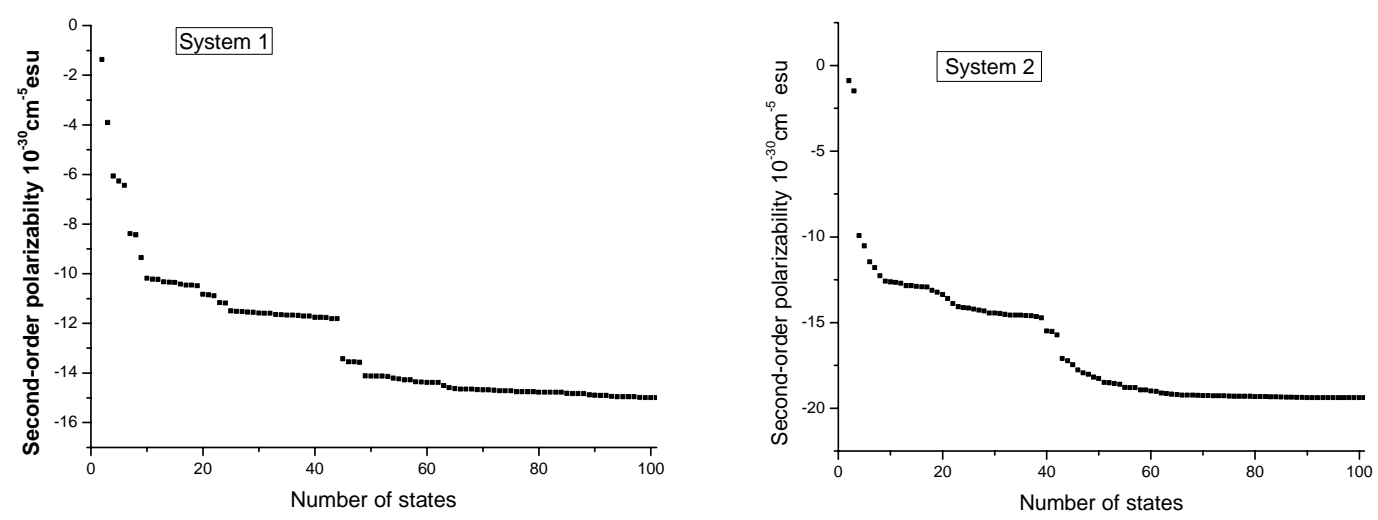

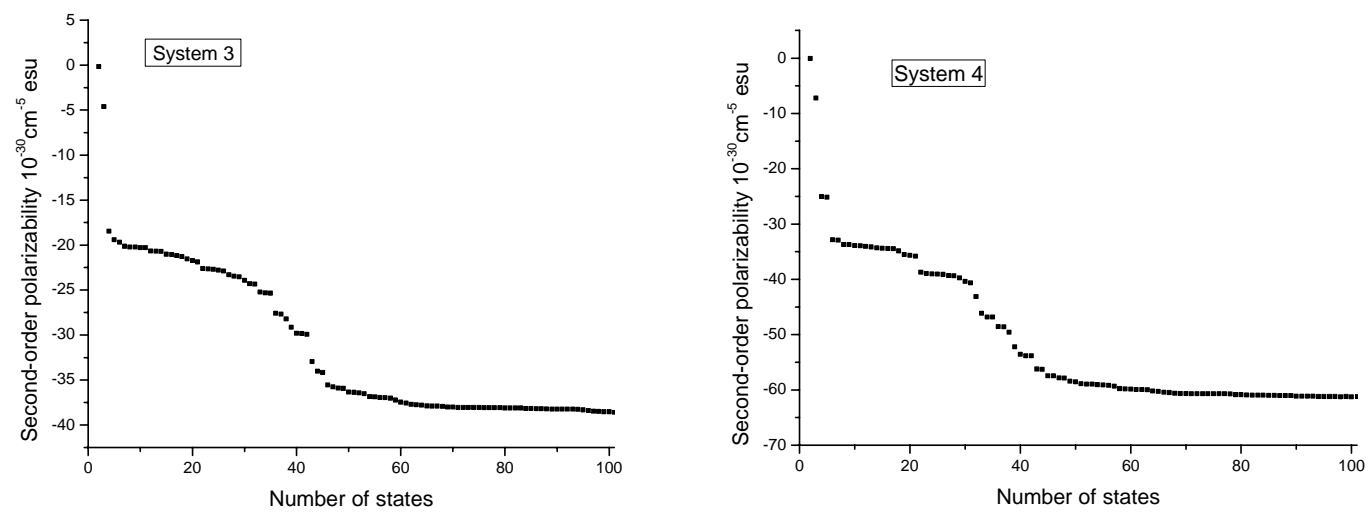

Figure 1. Plot of the $\beta_{\text {vec }}$ values vs the number of states for the studied system 1-4.
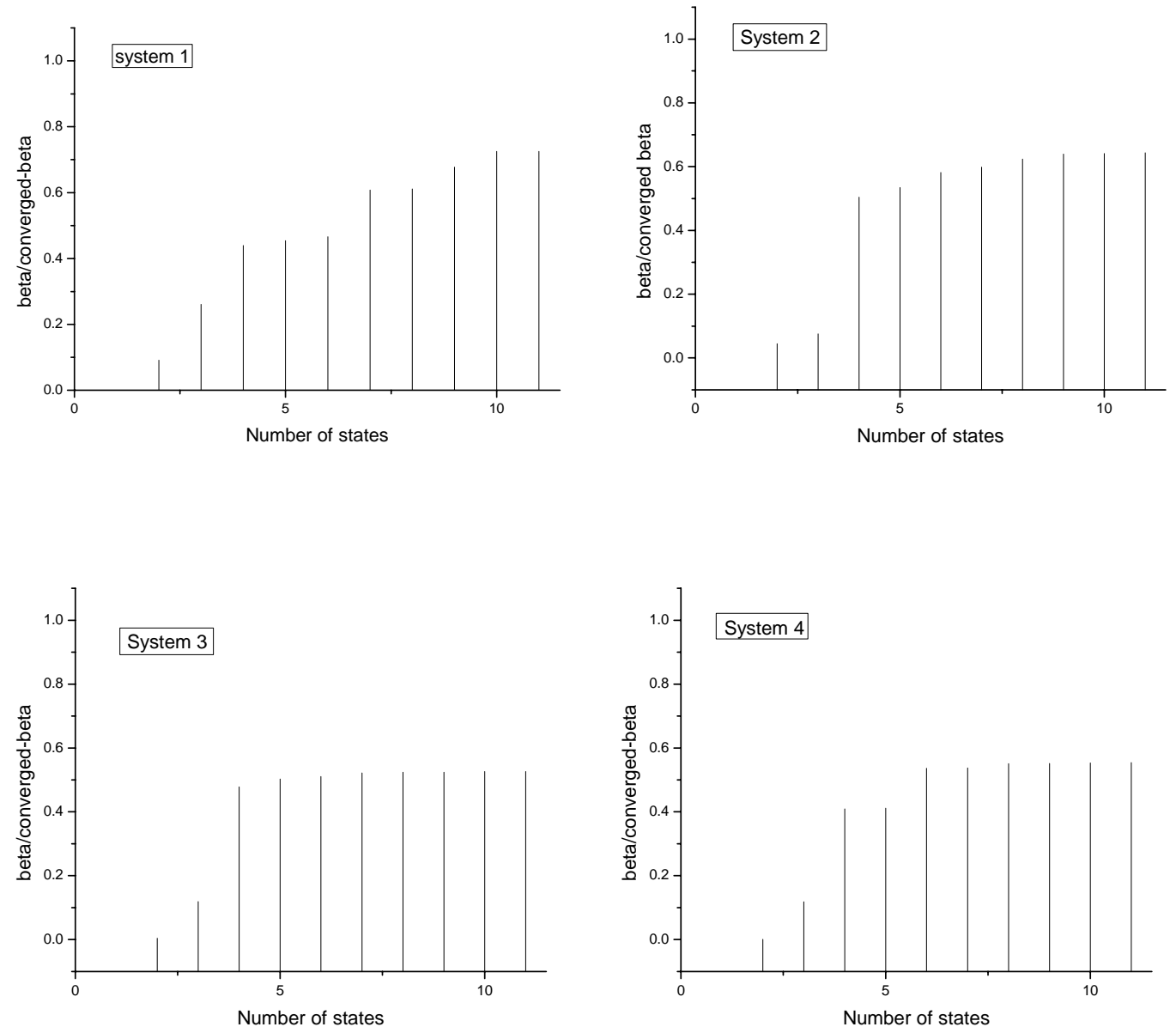

Figure 2. The percentage contribution of the $1^{\text {st }}$ ten excited states (beta/converged-beta)

7. The contribution to the second-order polarizabilities for each states (Percentage), $\Delta \mu$ is the difference between the ground state and excited state (Debye). 


\begin{tabular}{cccccc}
\hline System & & $\lambda$ & $f$ & $\Delta \mu$ & Contribution $(\%)$ \\
& & & & & \\
\hline 1 & 8 & 440 & 0.1892 & -5.43 & 2.1 \\
& 9 & 351 & 0.1298 & -5.31 & 7.1 \\
& 22 & 338 & 0.1185 & -5.32 & 5.8 \\
& 24 & 332 & 0.1470 & -5.13 & 6.6 \\
& 44 & 276 & 1.2447 & -5.34 & 33.7 \\
2 & 3 & 387 & 0.1373 & -29.53 & 42.7 \\
& 39 & 288 & 0.3727 & -2.36 & 3.8 \\
& 42 & 283 & 0.7543 & -2.21 & 6.9 \\
& 44 & 279 & 0.1149 & -2.55 & 1.2 \\
& 45 & 275 & 0.1212 & -3.42 & 1.6 \\
& 48 & 274 & 0.1140 & -1.93 & 0.8 \\
30 & 50 & 268 & 0.1599 & -2.16 & 1.2 \\
& 33 & 310 & 0.1460 & -5.55 & 5.6 \\
& 35 & 305 & 0.3751 & -5.58 & 14.5 \\
& 38 & 299 & 0.1488 & -6.46 & 6.0 \\
& 39 & 298 & 0.1509 & -4.65 & 4.3 \\
& 42 & 287 & 0.7161 & -4.96 & 19.6 \\
& 43 & 286 & 0.2848 & -4.44 & 6.9 \\
& 45 & 282 & 0.3208 & -5.31 & 8.9 \\
4 & 49 & 275 & 0.1104 & -4.96 & 2.6 \\
& 3 & 746 & 0.1330 & -8.97 & 29.0 \\
& 5 & 598 & 0.1174 & -8.51 & 12.5 \\
& 21 & 356 & 0.1943 & -9.18 & 4.7 \\
& 30 & 308 & 0.3016 & -2.04 & 1.1 \\
& 32 & 306 & 0.3759 & -7.81 & 4.9 \\
& 35 & 302 & 0.2268 & -7.72 & 2.8 \\
& 37 & 298 & 0.1257 & -7.98 & 1.6 \\
& 38 & 296 & 0.3702 & -7.69 & 4.3 \\
& 39 & 293 & 0.2154 & -6.94 & 2.2 \\
& 42 & 287 & 0.3986 & -7.05 & 3.8 \\
44 & 284 & 0.1910 & -7.52 & 1.9 \\
\hline \multirow{4}{*}{4} & & & & \\
& & & & \\
& 43 &
\end{tabular}

